\title{
Uremic pruritus and serum brain-derived neurotrophic factor in diabetic and non-diabetic haemodialysis patients
}

\author{
Mirosław Śnit ${ }^{1}$, Katarzyna Nabrdalik ${ }^{1}$, Radosław Gawlik², Grzegorz Wystrychowski ${ }^{1}$, Beata Łącka-Gaździk ${ }^{1}$, \\ Roman Kuźniewicz ${ }^{1}$, Janusz Gumprecht ${ }^{1}$, Tomasz Wielkoszyński ${ }^{3}$, Beata Łabuz-Roszak ${ }^{4}$, Władysław Grzeszczak ${ }^{1}$
}

\author{
${ }^{1}$ Department of Internal Medicine, Diabetology and Nephrology, Faculty of Medical Sciences in Zabrze, Medical University of Silesia \\ in Katowice, Poland \\ 2Department of Internal Medicine, Allergology and Clinical Immunology, Faculty of Medical Sciences in Katowice, Medical University \\ of Silesia, Katowice, Poland \\ ${ }^{3}$ Department of Laboratory Medicine, Pulmonology Hospital, Tarnowskie Góry, Poland \\ ${ }^{4}$ Department of Basic Medical Sciences, Faculty of Health Sciences in Bytom, Medical University of Silesia in Katowice, Poland
}

Adv Dermatol Allergol 2020; XXXVII (6): 932-937

DOI: https://doi.org/10.5114/ada.2019.87707

\begin{abstract}
Introduction: Even though uremic pruritus (UP) is very troublesome for haemodialysis (HD) patients, its underlying mechanism is not fully understood.

Aim: Due to the possible role of brain-derived neurotrophic factor (BDNF) and its higher serum concentration in haemodialysis diabetic patients compared to non-diabetic ones, this study is aimed to evaluate its association with UP among diabetic and non-diabetic patients on maintenance HD.

Material and methods: A total of 94 patients were enrolled into the study. A visual analogue scale (VAS) was used to assess pruritus.

Results: No differences were found between the observed study groups in terms of BDNF serum concentration, other biochemical markers, sleep disturbances, or pruritus presentation.

Conclusions: BDNF serum concentration was not found to be associated with UP among HD patients, however further studies are worth performing on a larger group of individuals.
\end{abstract}

Key words: brain-derived neurotrophic factor, diabetes mellitus, haemodialysis, pruritus.

\section{Introduction}

While the association of uraemia with pruritus has been recognized for decades, its pathophysiologic mechanisms remain unknown, preventing the development of an effective treatment. Uremic pruritus (UP) is a very common condition, described as any itch that is related to kidney disease unless there is a clear alternative explanation [1]. The Dialysis Outcomes and Practice Patterns Study (DOPPS), a large-scale observational study of haemodialysis (HD) patient outcomes performed in

Twelve different countries, indicated that $41.7 \%$ of the examined patients from the years 2002 to 2003 presented with moderate to extreme pruritus. This percentage is lower than observed in earlier data from DOPPS-I, collected from 1996 to 2001, where the prevalence rate of pruritus was $44.9 \%$. Even though the study was performed more than a decade ago, it provides the most complete epidemiological data to date [2]. UP is not only important due to its significant, well-known, negative impact on quality of life, but even more so because of its independent association with a 17\% higher mortality risk, mainly attributed to sleep quality disturbances [2]. The pathophysiology of UP is still poorly understood, however it is known that it is likely to be multifactorial. Among other factors, iron deficiency, anaemia, and metabolic disturbances such as hypercalcemia, hyperphosphatemia, and secondary hyperparathyroidism have been proposed to be related to pruritus, however published results are conflicting [3-6]. Additionally, a new hypothesis to explain the underlying pathophysiology of UP has arisen recently, which considers UP to be an in-

\footnotetext{
Address for correspondence: Beata Łabuz-Roszak MD, PhD, Assoc. Prof., Department of Basic Medical Sciences, Faculty of Health Sciences, Medical University of Silesia, 18 Piekarska St, 41-902 Bytom, Poland, e-mail: beatamaria.pl@hoga.pl Received: 9.08.2018, accepted: 29.04.2019.
} 
flammatory systemic disease [7, 8]. In uremic subjects, pro-inflammatory cytokines, such as interleukin (IL) 1 , IL-6, tumor necrosis factor $\alpha$ (TNF- $\alpha)$, and interferon $\gamma$ (IFN- $\gamma$ ), show higher values. On the other hand, anti-inflammatory cytokines including IL-2, IL-4, IL-5, and IL-12 are decreased in subjects on maintenance HD [9]. Decreased renal function predisposes patients to cytokine accumulation, which may contribute to the pro-inflammatory milieu in those patients. Antihistamines do not improve itching; therefore, it is possible that UP is mediated throughout histamine-independent pathways. Apart from histamines, there are other neurotrophin mediators which have been found to play a role in the pathophysiology of itch [10]. Neurotrophins, namely brain-derived neurotrophic factor (BDNF), nerve growth factor (NGF), neurotrophin-3 (NT-3), and neurotrophin-4/5 (NT-4/5), belong to a class of growth factors that modulate survival, differentiation, and maintenance of nerve cells. However, due to the common ectodermal origin of the nervous system and skin epithelium, growth factors which regulate the development and function of neurons may also be involved in the control of skin homeostasis [11]. It has recently been proven that neurotrophins may be involved in the pathogenesis of different pathological skin conditions via neurogenic inflammatory processes [12]. These growth factors in skin are synthesized and released by eosinophils, mast cells, keratinocytes, and fibroblasts [13]. It has been also found that serum concentration of BDNF is increased in patients with atopic dermatitis as well as among patients with urticaria and correlate with disease severity $[14,15]$. Some studies indicate that serum BDNF concentration may be associated with systemic or peripheral inflammatory conditions or metabolic disturbances, including diabetes [16-20]. It has also been observed that serum BDNF is increased in HD patients, especially in those with diabetes, and the authors of this study hypothesize that concentrations of BDNF may reflect inflammatory status [21].

\section{Aim}

Taking into account the immune hypothesis of UP and the role of BDNF serum concentration in inflammation, metabolic disease, and atopic dermatitis, we aimed to conduct a study which is, to the best of our knowledge, the first one to investigate the association of serum BDNF concentration with UP in diabetic and non-diabetic HD patients.

\section{Material and methods}

\section{Subjects}

There were 94 patients on maintenance HD who presented with pruritus and were invited to participate in the study. Patients were recruited from 2 dialysis centres in Zabrze, Poland. The inclusion criteria for the studied group were as follows: pruritus, end-stage renal disease (ESRD) on maintenance HD for a year or longer, age $\geq 18$ years, lack of primary skin disease, and informed consent to participation in the study. We excluded patients with primary skin diseases, infectious diseases, and those on immunosuppressant therapy. HD was performed 3 times a week for $4 \mathrm{~h}$ using high-flux polysulfone membrane dialyzers. The quality of dialysis was assessed during the study period by calculating Kt/V (HD adequacy ratio) for all patients. Based on the medical interview and medical documentation, the following data were analysed: duration of chronic kidney disease (CKD) and HD treatment, type of dialysis access, and concomitant diseases. Patients were divided into subgroups depending on whether they had diabetes mellitus or not. The study was performed according to the Helsinki Declaration and was approved by the Ethical Committee of the Medical University of Silesia.

\section{Study design}

Each eligible patient who signed informed consent to participation in the study self-reported an 11-degree visual analogue scale (VAS) estimating the severity of pruritus [22-24]. The VAS was performed on a randomly selected day and patients completed the questionnaires during their HD sessions or while they were physically in the dialysis unit under staff supervision. The scale uses an analogue format that is a continuous range of values. Patients were asked to make a mark on the 100-mm length, horizontal line. Afterwards the line was measured and recorded in centimetres where 0 denoted no pruritus at all, $>0$ and $<4$ indicated mild pruritus, $\geq 4$ and $<7$ indicated moderate pruritus, $\geq 7$ and $<9$ indicated severe pruritus, and $\geq 9$ indicated very severe pruritus [24, 25]. Patients were asked to evaluate itching over the previous 30 days. They also noted sleep disturbances related to pruritus over the same time period.

The laboratory blood examination was performed according to a protocol of routine blood tests in dialyzed patients and measured automatically in the dialysis ward's clinical laboratory by routine methods. The blood was taken before the HD session. Serum, which remained after performing routine tests, was used to assess BDNF concentration. BDNF concentration was measured using the immunoenzymatic method with monoclonal antibodies in blood serum (BDNF Emax ${ }^{\circledast}$ Immuno Assay System, Promega Corporation, Madison, USA) and expressed in $\mathrm{pg} / \mathrm{ml}$. All measured laboratory parameters are listed in Table 1.

\section{Statistical analysis}

Descriptive statistics for continuous parameters were expressed in arithmetic means \pm SD or medians (interquartile range). The qualitative traits were presented as absolute numbers or percentages. The following tests 
M. Śnit, K, Nabrdalik, R. Gawlik, G. Wystrychowski, B. Łącka-Gaździk, R. Kuźniewicz, J. Gumprecht, T. Wielkoszyński, B. Łabuz-Roszak, W. Grzeszczak

Table 1. Laboratory findings among studied patients

\begin{tabular}{|c|c|c|c|c|c|c|c|}
\hline Parameter & $\begin{array}{l}\text { All patients } \\
\quad(n=94)\end{array}$ & $\begin{array}{c}\text { Men } \\
(n=52)\end{array}$ & $\begin{array}{l}\text { Women } \\
(n=42)\end{array}$ & $\begin{array}{l}\text { Men vs. } \\
\text { women } \\
P \text {-value }\end{array}$ & $\begin{array}{l}\text { Patients with DM } \\
\quad(n=25)\end{array}$ & $\begin{array}{c}\text { Patients without } \\
\text { DM } \\
(n=69)\end{array}$ & $\begin{array}{c}\text { Patients } \\
\text { with DM } \\
\text { vs. patients } \\
\text { without DM } \\
P \text {-value }\end{array}$ \\
\hline $\begin{array}{l}\text { Blood haemoglobin } \\
{[\mathrm{g} / \mathrm{l}]}\end{array}$ & $11.01 \pm 1.38$ & $11.08 \pm 1.31$ & $10.89 \pm 1.50$ & 0.53 & $10.76 \pm 1.12$ & $11.30 \pm 1.46$ & 0.14 \\
\hline Serum iron $[\mu \mathrm{g} / \mathrm{dl}]$ & $45.44 \pm 28.6$ & $46.43 \pm 31.93$ & $43.85 \pm 22.52$ & 0.68 & $43.92 \pm 33.87$ & $43.85 \pm 23.75$ & 0.99 \\
\hline $\begin{array}{l}\text { Serum ferritin } \\
{[\mathrm{ng} / \mathrm{ml}]}\end{array}$ & $\begin{array}{c}563.12 \\
(243.2-1063.1)\end{array}$ & $\begin{array}{c}450.83 \\
(174.15-845.8)\end{array}$ & $\begin{array}{c}674.01 \\
(331.3-1067.1)\end{array}$ & 0.13 & $\begin{array}{c}421.02 \\
(167.3-914.9)\end{array}$ & $\begin{array}{c}538.80 \\
(219.2-1011.0)\end{array}$ & 0.56 \\
\hline $\begin{array}{l}\text { Serum transferrin } \\
{[\mathrm{mg} / \mathrm{dl}]}\end{array}$ & $163.13 \pm 6.74$ & $165.64 \pm 38.35$ & $158.91 \pm 4.05$ & 0.40 & $177.61 \pm 34.15$ & $163.67 \pm 32.67$ & 0.13 \\
\hline Serum albumin $[g / l]$ & $3.69 \pm 0.49$ & $3.72 \pm 0.41$ & $3.73 \pm 0.38$ & 0.90 & $3.65 \pm 0.35$ & $3.82 \pm 0.32$ & 0.06 \\
\hline Serum CRP [mg/l] & $\begin{array}{c}6.51 \\
(2.9-11.2)\end{array}$ & $\begin{array}{c}4.25 \\
(4-5.9)\end{array}$ & $\begin{array}{c}3.95 \\
(2.4-8)\end{array}$ & 0.11 & $\begin{array}{c}5.52 \\
(2.9-10.9)\end{array}$ & $\begin{array}{c}6.54 \\
(2.8-20.7)\end{array}$ & 0.78 \\
\hline $\begin{array}{l}\text { Serum total calcium } \\
{[\mathrm{mmol} / \mathrm{l}]}\end{array}$ & $2.16 \pm 0.18$ & $2.19 \pm 0.18$ & $2.16 \pm 0.17$ & 0.21 & $2.15 \pm 0.15$ & $2.17 \pm 0.20$ & 0.71 \\
\hline $\begin{array}{l}\text { Serum phosphate } \\
{[\mathrm{mg} / \mathrm{dl}]}\end{array}$ & $5.11 \pm 1.69$ & $5.02 \pm 1.52$ & $5.26 \pm 1.95$ & 0.51 & $4.31 \pm 1.10$ & $4.43 \pm 1.41$ & 0.73 \\
\hline $\begin{array}{l}\text { Calcium } \times \\
\text { phosphate product } \\
{\left[\mathrm{mg}^{2} / \mathrm{dl}^{2}\right]}\end{array}$ & $44.01 \pm 4.32$ & $43.94 \pm 13.04$ & $44.13 \pm 16.31$ & 0.95 & $45.06 \pm 11.63$ & $46.81 \pm 14.70$ & 0.82 \\
\hline Plasma PTH [pg/ml] & $\begin{array}{c}175.01 \\
(91.0-438.7)\end{array}$ & $\begin{array}{c}154.45 \\
(88.7-384.7)\end{array}$ & $\begin{array}{c}280.35 \\
(94.1-446.7)\end{array}$ & 0.24 & $\begin{array}{c}136.60 \\
(76.7-318.0)\end{array}$ & $\begin{array}{c}225.61 \\
(101.3-477.3)\end{array}$ & 0.22 \\
\hline $\mathrm{Kt} / \mathrm{V}, 1 / 1$ & $\begin{array}{c}1.38 \\
(1.31-1.59)\end{array}$ & $\begin{array}{c}1.36 \\
(1.29-1.46)\end{array}$ & $\begin{array}{c}1.34 \\
(1.27-1.44)\end{array}$ & 0.72 & $\begin{array}{c}1.42 \\
(1.34-1.56)\end{array}$ & $\begin{array}{c}1.39 \\
(1.31-1.67)\end{array}$ & 0.76 \\
\hline $\begin{array}{l}\text { Serum total BDNF } \\
{[\mathrm{pg} / \mathrm{ml}]}\end{array}$ & $\begin{array}{l}2753.93 \\
\pm 634.70\end{array}$ & $\begin{array}{l}2769.55 \\
\pm 629.63\end{array}$ & $\begin{array}{l}2729.85 \\
\pm 650.39\end{array}$ & 0.77 & $2682.95 \pm 648.53$ & $2743.61 \pm 574.49$ & 0.69 \\
\hline
\end{tabular}

Mean value for each parameter is given with SD or medians (interquartile range) in brackets. Kt $N$ - haemodialysis adequacy ratio, DM - diabetes mellitus.

were used: the $\chi^{2}$ test, $t$-Student test, and the MannWhitney U-test, when appropriate. A $p$-value less than 0.05 was considered as significant. All analyses were performed using Statistica v. 12.5.

\section{Results}

Out of 180 patients on maintenance HD treated in two dialysis units participating in the study, we included 94 (males $n=52,55.3 \%$ ) who presented with pruritus, which constituted $52 \%$ of all patients. The mean \pm SD age of patients was $59.1 \pm 13.4$ years and mean \pm SD time of dialysis treatment was $4.6 \pm 3.6$ years. Demographic characteristics of the patients and selected information from the medical records are presented in Table 2. The most common aetiology of ESRD was hypertension (27.7\%) and diabetes (26.6\%). A portion of the subjects were affected by non-renal diseases that could arguably contribute to pruritus (liver disease, hypothyroidism, hyperparathyroidism). Clinical characteristics of patients are also presented in Table 2. A total of $39.4 \%$ of patients had sleep disorders due to the itching sensation (Table 3). The intensity of itching was reported as mild (Table 3). There were no statistically significant differences observed in the occurrence or intensity of pruritus, nor frequency of sleep disorders with regard to diabetes status (Table 3 ). There were no significant differences found in terms of biochemical parameters related to dialysis treatment and iron or calcium-phosphorus status between diabetic and non-diabetic patients or between men and women (Table 1).

\section{Discussion}

In our study, we found that UP was present in more than a half of the patients on maintenance HD, which is slightly higher than the prevalence described previously in the DOPPS [2]. Studies assessing pruritus occurrence in diabetes itself are rare and those performed decades ago indicate that pruritus is not common in this group of patients (except for pruritus vulvae among women) with a prevalence of generalized or localized pruritus up to several percent of the studied population [26]. As 
pruritus is very subjective, it is challenging to measure it objectively. For the purpose of the study, we have used VAS to assess pruritus intensity. The scale was first developed by Hayes and Petterson in 1921 to assess pain [22], however recently it has been evaluated as a reliable tool for the assessment of pruritus intensity [24]. Pruritus intensity in the studied group was categorized as mild ( $>0$ and $<4$ points in the VAS), which is similar to some of the prior studies $[27,28]$. However, the intensity is lower than observed in our previous study, where a mean \pm SD score in the VAS among HD patients was $4.9 \pm 2.47$, indicating not mild, but moderate pruritus [29]. These differences may be caused by the study protocol, where in both studies, patients were asked to complete the VAS only once, whilst repeating it 2-3 times during a set time period could provide more objective outcomes. There have been some risk factors previously identified for pruritus among HD patients, which include male gender, high level of blood urea nitrogen, and elevated phosphorus levels [28]. We have found no significant differences related to the diabetes status in regards to serum BDNF concentration or other biochemical parameters (Table 1). This finding is in contrast to results obtained by Shin et al. [21], who observed a significantly higher serum BDNF concentration in diabetic HD patients than in non-diabetic ones. Consequently, they postulated that serum BDNF concentration is increased in HD patients with diabetes to compensate hyperinsulinemia and insulin resistance. However, there is a controversy as to whether serum BDNF concentration is higher in individuals with diabetes than in ones without metabolic glucose disturbances who are not undergoing dialysis treatment. A previous study by Suwa et al. showed that the serum BDNF concentration was higher in newly-diagnosed type 2 diabetic patients than in controls without diabetes [18], but Fujinami et al. reported that the serum BDNF concentration was significantly lower in patients with advanced type 2 diabetes compared to control subjects [30]. Neither of the mentioned studies included patients with end-stage renal disease (ESRD). In our study, the presence of diabetes alone seemed unlikely to account for the elevated concentration of serum BDNF. The serum BDNF concentration observed in the presented study was approximately 6 times higher compared to the ranges observed previously among healthy subjects and approximately 3 times higher compared to the ranges observed among patients on maintenance HD as indicated in the study by Shin et al. [21]. On the other hand, in the study by Zoladz et al., the BDNF serum concentration value was similar to the one presented in our study [31]. It is difficult to explain the nature of the observed discrepancies, however one of the explanations may be that the blood for biochemical analysis was taken just before the HD session, not in the morning in a fasting state, which could influence BDNF concentration. Additionally, in the study by Shin et al., the plasma, rather than the serum concentration of BDNF, was studied, which complicates the comparison of the outcomes obtained. Multiple factors may lead to an increased serum BDNF concentration in a uremic state and one explanation may be a constant

Table 2. Characteristics of the study group

\begin{tabular}{lc}
\hline Parameter & Results \\
\hline All subjects, $n$ (\%): & $94(100)$ \\
\hline Women & $42(44.7)$ \\
\hline Men & $52(55.3)$ \\
\hline Age [years], mean \pm SD & $59.1 \pm 13.4$ \\
\hline Cause of chronic kidney disease, $n$ (\%): & $7(7.4)$ \\
\hline Unclear cause & $5(5.3)$ \\
\hline Type 1 diabetic nephropathy & $20(21.3)$ \\
\hline Type 2 diabetic nephropathy & $14(14.9)$ \\
\hline Chronic glomerulonephritis & $26(27.7)$ \\
\hline Hypertensive nephropathy & $8(8.5)$ \\
\hline Chronic interstitial nephritis & $1(1.1)$ \\
\hline Kidney stones & $13(13.8)$ \\
\hline Polycystic kidney disease & $9.4 \pm 8.4$ \\
\hline Duration of chronic kidney disease [years], \\
mean \pm SD & \\
\hline Duration of HD treatment [years], mean \pm SD & $4.6 \pm 3.6$ \\
\hline Liver disease, $n$ (\%): & $2(2.1)$ \\
\hline Type B hepatitis & $6(6.4)$ \\
\hline Type C hepatitis & $3(3.2)$ \\
\hline Liver cirrhosis & $3(3.2)$ \\
\hline Other diseases of liver and biliary tract & $11(11.7)$ \\
\hline Other diseases, $n$ (\%): & \\
\hline Hypothyroidism & \\
\hline Hyperparathyroidism & \\
\hline Aialysis access, $n$ (\%): & \\
\hline Central venous catheter & \\
\hline number of patients, \% - percent of investigated patients. & \\
\hline
\end{tabular}

Table 3. Self-reported pruritus and sleep disorders among patients with pruritus

\begin{tabular}{lcccc}
\hline Parameter & All patients $(n=94)$ & Patients with DM $(n=25)$ & Patients without DM $(n=69)$ & DM vs. non-DM, $p$-value \\
\hline Intensity of pruritus, VAS & $2.08 \pm 2.95$ & $2.43 \pm 3.25$ & $1.98 \pm 2.86$ & 0.75 \\
\hline Sleep disorders, $n(\%)$ & $37(39.4)$ & $11(44)$ & $27(39.1)$ & 0.94 \\
\hline
\end{tabular}

VAS - visual analogue scale, $n$-number of patients, DM - diabetes mellitus. 
inflammatory condition among HD patients [21, 32]. Shin et al. showed that serum cytokine levels were increased in HD patients but not in controls [21]. A higher secretion of BDNF in uremic inflammation is not unexpected in view of its production by activated antigen-specific $T$ cells, B cells, and monocytes and the activation of the immune system in the uremic state involving both T lymphocytes and monocytes [33, 34].

We did not find any differences in the BDNF serum concentration between male and female HD subjects. This finding is in agreement with results obtained by Shin et al., but in contrast to the results obtained by Wang et al., who found a significantly higher serum BDNF concentration in female patients than in male patients [21, 35]. The two mentioned studies are the only ones where the BDNF concentration was studied among patients on maintenance HD and took possible gender differences under consideration.

The presented study has several limitations. First of all, there is a small sample size and larger groups of patients should be included in order to be sure that the outcomes are relevant. The performance of the study among patients coming from only 2 dialysis centres is another limitation that may influence the study outcomes.

\section{Conclusions}

There are not many studies performed to date that have taken under consideration BDNF as a factor that could take part in the pathogenesis of UP and their outcomes are conflicting. According to the immune hypothesis, BDNF or other neurotrophins can play an important role in UP, and even though we were not able to prove an association of BDNF concentration with UP in our study, there is a tremendous need for further studies trying to disentangle the underlying pathophysiological mechanisms of UP in order to find effective treatment modalities.

\section{Conflict of interest}

The authors declare no conflict of interest.

\section{References}

1. Mettang T, Kremer AE. Uremic pruritus. Kidney Int 2015; 87: 685-91.

2. Pisoni RL, Wikstrom B, Elder SJ, et al. Pruritus in haemodialysis patients: International results from the Dialysis Outcomes and Practice Patterns Study (DOPPS). Nephrol Dial Transplant 2006; 21: 3495-505.

3. Cho YL, Liu HN, Huang TP, et al. Uremic pruritus: roles of parathyroid hormone and substance P. J Am Acad Dermatol 1997; 36: 538-43.

4. Chou FF, Ho JC, Huang SC, et al. A study on pruritus after parathyroidectomy for secondary hyperparathyroidism. J Am Coll Surgeons 2000; 190: 65-70.
5. Hiroshige K, Kabashima N, Takasugi M, et al. Optimal dialysis improves uremic pruritus. Am J Kidney Dis 1995; 25: 413-9.

6. Virga G, Visentin I, La Milia V, et al. Inflammation and pruritus in haemodialysis patients. Nephrol Dial Transplant 2002; 17: 2164-9.

7. Kimmel M, Alscher DM, Dunst R, et al. The role of microinflammation in the pathogenesis of uraemic pruritus in haemodialysis patients. Nephrol Dial Transplant 2006; 21: 749-55.

8. Fallahzadeh MK, Roozbeh J, Geramizadeh B, et al. Interleukin-2 serum levels are elevated in patients with uremic pruritus: a novel finding with practical implications. Nephrol Dial Transplant 2011; 26: 3338-44.

9. Cohen SD, Phillips TM, Khetpal P, et al. Cytokine patterns and survival in haemodialysis patients. Nephrol Dial Transplant 2010; 25: 1239-43.

10. Raap U, Stander S, Metz M. Pathophysiology of itch and new treatments. Curr Opin Allergy Clin Immunol 2011; 11: 420-7.

11. Pincelli C, Yaar M. Nerve growth factor: its significance in cutaneous biology. J Invest Dermatol Symp Proc 1997; 2: 31-6.

12. Botchkarev VA, Yaar M, Peters EM, et al. Neurotrophins in skin biology and pathology. J Invest Dermatol 2006; 126: 1719-27.

13. Botchkarev VA, Metz M, Botchkareva NV, et al. Brain-derived neurotrophic factor, neurotrophin-3, and neurotrophin-4 act as "epitheliotrophins" in murine skin. Lab Invest 1999; 79: 557-72.

14. Raap U, Werfel T, Goltz C, et al. Circulating levels of brainderived neurotrophic factor correlate with disease severity in the intrinsic type of atopic dermatitis. Allergy 2006; 61: 1416-8.

15. Rossing K, Novak N, Mommert S, et al. Brain-derived neurotrophic factor is increased in serum and skin levels of patients with chronic spontaneous urticaria. Clin Exp Allergy 2011; 41: 1392-9.

16. Chimienti G, Mezzapesa A, Rotelli MT, et al. Plasma concentrations but not serum concentrations of brain-derived neurotrophic factor are related to pro-inflammatory cytokines in patients undergoing major abdominal surgery. Clin Biochem 2012; 45: 631-6.

17. Boyuk B, Degirmencioglu S, Atalay H, et al. Relationship between levels of brain-derived neurotrophic factor and metabolic parameters in patients with type 2 diabetes mellitus. J Diabetes Res 2014; 2014: 978143.

18. Suwa M, Kishimoto H, Nofuji Y, et al. Serum brain-derived neurotrophic factor level is increased and associated with obesity in newly diagnosed female patients with type 2 diabetes mellitus. Metabolism 2006; 55: 852-7.

19. Manni L, Nikolova V, Vyagova D, et al. Reduced plasma levels of NGF and BDNF in patients with acute coronary syndromes. Int J Cardiol 2005; 102: 169-71.

20.Grimsholm O, Rantapaa-Dahlqvist S, Dalen T, et al. BDNF in RA: downregulated in plasma following anti-TNF treatment but no correlation with inflammatory parameters. Clin Rheumatol 2008; 27: 1289-97.

21. Shin SJ, Yoon HE, Chung S, et al. Plasma brain-derived neurotrophic factor in hemodialysis patients. Int I Med Sci 2012; 9: $772-7$

22. Hayes MHS, Patterson DG. Experimental development of the graphic rating method. Psychol Bull 1921; 18: 98-9.

23. Miller MD, Ferris DG. Measurement of subjective phenomena in primary care research: the Visual Analogue Scale. Fam Pract 1993; 13: 15-24. 
24. Reich A, Heisig M, Phan NQ, et al. Visual analogue scale: evaluation of the instrument for the assessment of pruritus. Acta Derm Venerol 2012; 92: 497-501.

25. Scrimshaw SV, Maher C. Responsiveness of visual analogue and McGill pain scale measures. J Manipulative Physiol Ther 2001; 24: 501-4.

26. Neilly JB, Martin A, Simpson N, et al. Pruritus in diabetes mellitus: investigation of prevalence and correlation with diabetes control. Diabetes Care 1986; 9: 273-5.

27. Min JW, Kim SH, Kim YO, et al. Comparison of uremic pruritus between patients undergoing hemodialysis and peritoneal dialysis. Kidney Res Clin Practice 2016; 35: 107-13.

28. Narita I, Alchi B, Omori K, et al. Etiology and prognostic significance of severe uremic pruritus in chronic hemodialysis patients. Kidney Int 2006; 69: 1626-32.

29.Śnit M, Gawlik R, Łącka-Gaździk B, et al. Substance P and intensity of pruritus in hemodialysis and peritoneal dialysis patients. Med Sci Monitor 2013; 19: 723-32.

30. Fujinami A, Ohta K, Obayashi H, et al. Serum brain-derived neurotrophic factor in patients with type 2 diabetes mellitus: relationship to glucose metabolism and biomarkers of insulin resistance. Clin Biochem 2008; 41: 812-7.

31. Zoladz JA, Smigielski M, Majerczak J, et al. Hemodialysis decreases serum brain-derived neurotrophic factor concentration in humans. Neurochem Res 2012; 37: 2715-24.

32. Raap U, Deneka N, Bruder M, et al. Differential up-regulation of neurotrophin receptors and functional activity of neurotrophins on peripheral blood eosinophils of patients with allergic rhinitis, atopic dermatitis and nonatopic subjects. Clin Exp Allergy 2008; 38: 1493-8.

33. Kerschensteiner M, Gallmeier E, Behrens L, et al. Activated human T cells, B cells, and monocytes produce brain-derived neurotrophic factor in vitro and in inflammatory brain lesions: a neuroprotective role of inflammation? J Exp Med 1999; 189: 865-70.

34. Pereira R, Costa E, Goncalves M, et al. Neutrophil and monocyte activation in chronic kidney disease patients under hemodialysis and its relationship with resistance to recombinant human erythropoietin and to the hemodialysis procedure. Hemodial Int 2010; 14: 295-301.

35. Wang LJ, Chen CK, Hsu HJ, et al. Depression, 5HTTLPR and BDNF Val66Met polymorphisms, and plasma BDNF levels in hemodialysis patients with chronic renal failure. Neuropsychiatr Dis Treat 2014; 10: 1235-41. 